\title{
NEW CONVERGENCE RESULTS OF ITERATIVE METHODS FOR SET-VALUED MIXED VARIATIONAL INEQUALITIES
}

\author{
ABDEllatiF MOUdAFi AND MuHAMmad ASLAM NOOR
}

\begin{abstract}
An iterative method for solving set-valued variational inequalities is considered and its convergence properties are studied under strong monotonicity and coercivity conditions. The results obtained in this paper include, as a special case, some known results in this field.
\end{abstract}

Mathematics subject classification (1991): 49M45, 90C30, 65K10.

Key words and phrases: Variational inequalities, iterative methods, maximal monotone operators, co-coercivity condition.

\section{REFERENCES}

[1] AdLy S. AND OetTli W., Solvability of generalized nonlinera symmetric variational inequalities, J. Austral. Math. Soc. B 40 (1999), 289-300.

[2] AlvareZ, F. AND ATTOUCH H., The heavy ball with friction dynamical systems for convex constrained minimization problems, Prépublications de l’Université Montpelier II, 1998.

[3] BerTSEKAS D. P. Constrained Optimization and Lagrange Multiplier Methods, Academic Press, New York, 1982.

[4] BRÉZIS H., erateurs maximaux monotones et semi-groupes de contractions dans les espaces de Hilbert, North Holland, Amsterdam, Holland, 1973.

[5] FlAM S. D., Gradient approches to equilibrium, Lecture Notes In Economics and Mathematical Systems, 452, Springer-Verlag, Berlin, 49-60, 1997.

[6] GABAY D., Applications of the method of multipliers to variational inequalities, In Augmented Lagrangian Methods: Application to the solution of Boundary-Valued Problems, North Holland, Amsterdam, 299331, 1983.

[7] HAN S. P. AND LOU G., A parallel algorithm for a class of convex programs, SIAM J. Control Optim. 26 (1988), 345-355.

[8] LEMAIREB., On the convergence of some iterative methods for convex minimization, Recent Developements in Optimization, Lecture Notes in Economics and Mathematical Systems, 452 (1997), 154-167.

[9] LIONS P. L. AND MERCIER B., Splitting algorithms for the sum of two nonlinear operators, SIAM J. Num. Anal., 16 (1979), 964-979.

[10] MOUDAFI A. AND THÉRA M., Finding a zero of the sum of two maximal monotone operators, J. Optim. Theory Appl., 94 (1997), 425-448.

[11] Noor M. A., Monotone mixed variational inequalities, Math. Computer Modelling 29 (1999), 87-93.

[12] Noor M. A., Generalized mixed variational inequalities and resolvent equations, Positivity 1 (1997), $145-154$.

[13] OPIAL G. B., Weak convergence of sequence of successive approximations for nonexpansive mapping, Bull. Amer. Math. Soc., 77 (1967), 591-597.

[14] Panagiotopoulos P. D. and Stavroulakis G. E., New types of variational principles based on the notion of quasidifferentiability, Acta Mechanic, 94 (1994), 171-194.

[15] PASstY G. B., Ergodic convergence to a zero of the sum of monotone operators, J. Math. Anal. and Aplp. 72 (1979), 383-390.

[16] ROCKAFELLAR R. T., Monotone operators and the proximal algorithm, SIAM J. Control. Opt., 14(5) (1976), 877-898. 
[17] Sibony M., Methodes itteratives pour les equations aux derivees partielles nonlineaires de type monotone, Calcolo 7, 65-183.

[18] StAmPaCCHIA G., Formes bilineaires coercitives sur les ensembles convexes, C.R. Académies Sci. Paris 258, 413-416, 1964.

[19] TSENG P. CA modified forward-backward splitting method for maximal monotone mappings, SIAM J. Control Optim. (1998), to appear.

[20] ZHU D. L. AND MARCOTTE P. Co-coercivity and the role in the convergence of iterative schemes fo solving variational inequalities, SIAM J. on Optimization, 63 (1996), 714-726. 